\title{
A first-in-human, double-blind, placebo-controlled, randomized, dose escalation study of DWP05 I95, a novel TRPVI antagonist, in healthy volunteers
}

This article was published in the following Dove Press journal:

Drug Design, Development and Therapy

24 April 2017

Number of times this article has been viewed

\author{
Jieon Lee' \\ Bo-Hyung $\mathrm{Kim}^{2}$ \\ Kyung-Sang Yu' \\ Hee Sun Kim ${ }^{3}$ \\ ji Duck Kim ${ }^{4}$ \\ Joo-Youn Cho' \\ SeungHwan Lee' \\ Namyi Gu ${ }^{5}$ \\ 'Department of Clinical Pharmacology \\ and Therapeutics, Seoul National \\ University College of Medicine and \\ Hospital, ${ }^{2}$ Department of Clinical \\ Pharmacology and Therapeutics, \\ Kyung Hee University College \\ of Medicine and Hospital, Seoul, \\ ${ }^{3}$ Life Science Research Institute, \\ Daewoong Pharmaceutical Co. Ltd., \\ Yongin, ${ }^{4}$ Clinical Development Team, \\ Daewoong Pharmaceutical Co. \\ Ltd., Seoul, ${ }^{5}$ Department of Clinical \\ Pharmacology and Therapeutics, \\ Dongguk University College \\ of Medicine and Ilsan Hospital, \\ Goyang, Republic of Korea
}

Correspondence: SeungHwan Lee Department of Clinical Pharmacology and Therapeutics, Seoul National University College of Medicine and Hospital, I0I Daehak-ro, Jongno-gu, Seoul I 10-799, Republic of Korea

Tel +82 220722343

Fax +82 27429252

Email leejh413@snu.ac.kr

Namyi Gu

Department of Clinical Pharmacology and Therapeutics, Dongguk University College of Medicine and Ilsan Hospital, 8I 4 Siksa-dong, Ilsandong-gu, Goyang-si, Gyeonggi-do 0-773, Republic of Korea

Tel $+823|96| 8440$

Fax +82 31 9618449

Email namyi.gu@gmail.com
Objectives: DWP05195 is a transient receptor potential vanilloid 1 (TRPV1) antagonist developed for managing pain. The purpose of this study was to evaluate the pharmacodynamics pharmacokinetics, safety, and tolerability of DWP05195 in healthy subjects. This was a first-in-human randomized, double-blinded, placebo-controlled, dose escalation study.

Subjects and methods: DWP05195 or placebo was administered as a single dose of $10-600 \mathrm{mg}$ in the single-dose study and as 100-400 $\mathrm{mg}$ once daily for 8 days in the multipledose studies. Each study group consisted of 10 subjects (study drug-to-placebo ratio was 8:2). For pharmacodynamics assessment, the heat pain threshold (HPtr), heat pain tolerance (HPtol), perfusion intensity, and flare area ratio of cutaneous blood flow were measured. Safety and tolerability were evaluated throughout the study.

Results: The maximum plasma concentrations and area under the plasma concentration-time curve from zero to the last measurable time dose-dependently increased. HPtr and HPtol tended to increase more after DWP05195 administration than after placebo administration. HPtr and HPtol tended to dose-dependently increase after administration of DWP05195. Cutaneous blood flow was reduced as the dose of DWP05195 increased during the multiple-dose study. DWP05195 was well tolerated up to 600 and $400 \mathrm{mg}$ single- and multiple-dose administrations, respectively.

Conclusion: The pharmacological activity of DWP05195, measured using HPtr and HPtol, increased as expected in a dose-dependent manner owing to increased systemic exposure, indicating that DWP05195 can be used as a TRPV1 antagonist for pain management.

Keywords: DWP05195, TRPV1 antagonist, pain tolerance, pain threshold, capsaicin

\section{Introduction}

Pain is a common reason for visiting a physician. ${ }^{1}$ Nonsteroidal anti-inflammatory drugs (NSAIDs) and opioids are the currently available medications for the management of pain. ${ }^{2,3}$ However, NSAIDs are not efficacious in treating neuropathic pain. ${ }^{4}$ Furthermore, an effective dosage of opioids cannot be used to manage neuropathic pain in clinical settings. This is because opioids cause detrimental physiological problems, such as physical dependence, addiction, and tolerance, which decrease patients' quality of life. 5,6 The abovementioned limitations of NSAIDs and opioids are related to their pharmacological actions within the human body. ${ }^{7}$ Management of neuropathic pain is therefore an unmet medical need. Thus, it is necessary to develop an analgesic with a novel mechanism of action that can serve as a more effective alternative for the treatment of neuropathic pain. ${ }^{8,9}$

Transient receptor potential vanilloid 1 (TRPV1) has been reported to have a role in the development of neuropathic pain in several animal studies. ${ }^{10-12}$ TRPV1 is expressed 
in $\mathrm{C}$ fibers and A-delta fibers, which are responsible for the transmission of pain signals. ${ }^{13,14}$ The expression of TRPV1 has been reported to increase after nerve injury. ${ }^{15}$ Sensory neurons from mice lacking TRPV1 showed selective deficiency in their responses to noxious stimuli. ${ }^{2}$

DWP05195 is a TRPV1 antagonist that is under development by Daewoong Pharmaceutical Co. Ltd., Seoul, South Korea. DWP05195 has been reported to competitively inhibit transduction of the pain signal evoked by typical TRPV1 agonists such as capsaicin, endovanilloid, anandamide, and $N$-arachidonoyl dopamine. DWP05195 also generates analgesic effects in animal models with nerve injury and in animal models of diabetic neuropathy. Based on these findings, DWP05195 might be beneficial for pain management.

This study aimed to evaluate the pharmacodynamics (PD), pharmacokinetics (PKs), safety, and tolerability of DWP05195 after single and multiple oral administrations in healthy subjects.

\section{Subjects and methods Study subjects}

The eligible subjects were Korean healthy male volunteers aged between 20 and 45 years whose body mass index was in the range of $19.0-27.0 \mathrm{~kg} / \mathrm{m}^{2}$. Subjects were screened before enrollment to determine health based on previous medical history, physical examinations, 12-lead electrocardiograms (ECGs), vital signs, and laboratory tests. All subjects provided written informed consent before entering the study. Subjects were excluded if there was a history or evidence of any of the following: significant disease of the respiratory, cardiovascular, renal, gastrointestinal, hepatic, endocrine, hematologic, neurologic, or psychiatric systems; alcoholism or drug abuse; the use of any prescription drug; the use of any over-the-counter medication or herbal medication; and participation in any other clinical trial within 12 weeks before the scheduled administration of study drug. Subjects who had the following vital signs were also excluded: low blood pressure (systolic blood pressure $\leq 85 \mathrm{mmHg}$ ) and high blood pressure (systolic blood pressure $\geq 140 \mathrm{mmHg}$ or diastolic blood pressure $\geq 90 \mathrm{mmHg}$ ).

This study was performed in accordance with the principles of the Declaration of Helsinki and Korean Good Clinical Practice. The study protocol was reviewed and approved by the Ministry of Food and Drug Safety (Republic of Korea) and the Institutional Review Board of Seoul National University Hospital. The ClinicalTrials.gov registration numbers are NCT00969787 and NCT01094834 for the single- and multiple-dose studies, respectively.

\section{Study design}

The trial was conducted as a double-blinded, randomized, placebo-controlled, dose escalation study in Seoul National University Hospital. The trial consisted of two parts: a single ascending dose study and a multiple ascending dose study. A total of 121 subjects (single-dose study: 80 subjects and multiple-dose study: 40 subjects) were involved in the trial. In the single-dose study, subjects were assigned to one of eight groups receiving 10, 20, 50,100, 150, 250, 400, or $600 \mathrm{mg}$ DWP05195. In the multiple-dose study, subjects were assigned to one of four groups receiving 100, 200, 300, or $400 \mathrm{mg}$ DWP05195, and the study drug was administered once daily for 8 days. Each treatment group consisted of 10 subjects (study drug-to-placebo ratio was 8:2). All subjects were randomized to treatment, and a randomization code was generated by an independent external provider.

\section{Experimental pain (PD) assessments}

Heat pain threshold (HPtr) and heat pain tolerance (HPtol) were measured using a Thermal NeuroSensory Analyzer (TSA; Medoc Ltd., Udim, Israel) to evaluate DWP05195 PDs. ${ }^{16}$ HPtr was defined as the temperature at which the subjects first felt a painful stimulus. HPtol was defined as the temperature at which the subjects first felt maximum tolerable pain. The temperature of the TSA tip, which was attached to the measurement site of the lower arm, increased with constant velocity until $50^{\circ} \mathrm{C}$. The HPtr and HPtol were measured by the subject pushing a button on a response unit when the temperature of the TSA tip caused the first sensation of heat pain for HPtr and maximum tolerable pain for HPtol. The border of the measurement site was marked with a circle having a radius of $2.4 \mathrm{~cm}$ on the volar aspect of the lower arm. HPtr and HPtol measurements were repeated three times, and average values were used in the analyses.

HPtr and HPtol were measured in all groups, including the placebo group. HPtr and HPtol were measured on the normal skin before $(0 \mathrm{~h})$ and 3 and $8 \mathrm{~h}$ after DWP05195 administration in the single-dose study. In contrast, HPtr and HPtol were measured at 0 and $3 \mathrm{~h}$ on days 1 and 8 , respectively, after administration of the study drug in the multiple-dose study. On day 8, HPtr and HPtol were additionally measured on capsaicin-sensitized skin after measurements were taken on the normal skin before the first dose and $3 \mathrm{~h}$ after the eighth dose (skin sensitization test). To apply capsaicin cream, an engraved sticker with a $3 \mathrm{~cm}$ diameter circular hole was attached on the measurement site before application of capsaicin cream, and then, $\sim 1 \mathrm{~mL}$ of capsaicin cream $(0.025 \%$ capsaicin) was applied to the measurement site. The cream 
was left on the skin under occlusion for $30 \mathrm{~min}$ and then gently wiped off.

The cutoff temperature for either test was $50^{\circ} \mathrm{C}$ to prevent skin injury. In addition, PD values that were obtained at temperatures $>50^{\circ} \mathrm{C}$ before administering the drug were excluded from the analyses. ${ }^{17,18}$ Perfusion intensity (PI) and flare area ratio (FAR) were measured as the PD parameters of peripheral perfusion by using a PeriScan PIM 3 System (Perimed, Stockholm, Sweden). PD parameters were measured on non-sensitized skin $\left(\mathrm{HPtr}_{\text {non }}\right.$ and $\left.\mathrm{HPtol}_{\text {non }}\right)$ and on capsaicin-sensitized skin ( $\mathrm{HPtr}_{\text {cap }}$ and $\mathrm{HPtol}_{\text {cap }}$ ) in the multiple-dose study. To estimate interindividual variability more accurately, the actual values of HPtr and HPtol were individually corrected using baseline PD values of HPtr and HPtol, respectively, per the following equations: corrected $\mathrm{HPtr}=$ HPtr after study drug administration - HPtr before study drug administration and corrected HPtol = HPtol after study drug administration - HPtol before study drug administration where each value is the average of three measurements.

\section{PK assessments}

In the single-dose study, venous blood samples for the measurement of plasma DWP05195 concentrations were collected before administration and $0.33,0.67,1,1.5,2,3$, $4,6,10,16,24,36,48$, and $72 \mathrm{~h}$ after administration. Urine samples were collected just before study drug administration and $0-6,6-12,12-24,24-36,36-48$, and 48-72 $\mathrm{h}$ after study drug administration.

In the multiple-dose study, venous blood samples were collected at the following time points to evaluate the PK of DWP05195: before administration and 0.33, 0.67, 1, 1.5, 2, $3,4,6,10,16$, and $24 \mathrm{~h}$ after administration on day 1 . On days $3,4,5,6$, and 7 , blood samples were taken before drug administration. On day 8 , blood samples were taken before drug administration and at $0.33,0.67,1,1.5,2,3,4,6,10,16$, 24 36, 48, 72, and $96 \mathrm{~h}$ after administration. Urine samples were collected just before administering the study drug and at $0-6,6-12$, and $12-24 \mathrm{~h}$ on days 1 and 8 after administration of the drug. Blood samples were collected into heparinized tubes and centrifuged immediately to obtain plasma, which was stored at $-70^{\circ} \mathrm{C}$ until analysis.

The plasma and urine concentrations of DWP05195 were analyzed using high-performance liquid chromatography (Shimadzu System, Shimadzu, Japan) and mass spectrometry (API 4000 mass spectrometer; SCIEX, Framingham, MA, USA). A mixture of methanol and water (70:30) was used as the mobile phase, and the detection wavelength was set at $340 \mathrm{~nm}$. The concentration of DWP05195 was calculated using the ratio of the peak area of DWP05195 to the peak area of the internal standard. The lower limit of quantitation of DWP05195 was $5 \mu \mathrm{g} / \mathrm{L}$. The assay method was validated over ranges of 5-1,000 and 5-5,000 $\mu \mathrm{g} / \mathrm{L}$ for DWP05195 in plasma and urine, respectively. In the single-dose study, the precision of the assay method (using 2, 20, 600, and $1,000 \mu \mathrm{g} / \mathrm{L}$ quality control samples) was $<10 \%$ and the accuracy was $93.1 \%-104.9 \%$. In the multiple-dose study, the precision of the assay method (using 5, 50, 1,500, and $5,000 \mu \mathrm{g} / \mathrm{L}$ quality control samples) was $<5.3 \%$ and the accuracy was 94.4\%-109.6\%.

A non-compartmental method was used to analyze the individual PK parameters using Phoenix ${ }^{\circledR}$ software (ver 6.4; Pharsight Corp., Mountain View, CA, USA). PK analyses were performed using the actual time of blood sample collection. The maximum plasma concentration $\left(C_{\max }\right)$ of DWP05195 and the time at which $C_{\max }$ was observed $\left(\mathrm{T}_{\max }\right)$ were directly obtained from the plasma concentration-time profiles. The accumulation ratio of multiple dosing regimen was defined as the ratio of the area under the plasma concentration-time curve (AUC) within a dosing interval in a steady state $\left(\mathrm{AUC}_{\tau, \mathrm{ss}}\right)$ to $\mathrm{AUC}_{0-24 \mathrm{~h}}$ (the $\mathrm{AUC}$ on day 1$)$. Renal clearance and the amount of unchanged drug excreted in urine were evaluated from the urine samples.

\section{Safety and tolerability assessments}

Safety and tolerability assessments were conducted in all subjects who received one or more doses of the study drug. Safety and tolerability were evaluated based on data from physical examination, including vital signs such as systolic and diastolic blood pressures, pulse rate and temperature, ECG, and laboratory test results (hematology, clinical chemistry, thyroid function test, coagulation, and urinalysis) obtained throughout the study. Adverse events (AEs) were recorded from voluntary reports made by the subjects or by asking the subjects general health-related questions.

\section{Statistical analysis}

$\mathrm{SAS}^{\circledR}$ software (ver 9.3; SAS Institute Inc., Cary, NC, USA) was used for the statistical analyses, and the level of significance was set at 0.05 . To evaluate changes in PD parameters between the DWP05195-treated and placebo groups, analysis of covariance was performed using a mixed model with a covariate of the baseline values of those parameters. Because the HPtr or HPtol of some individuals was $>50^{\circ} \mathrm{C}$, the ratios between the numbers of the measurements $>50^{\circ} \mathrm{C}$ to all measurements were additionally compared among the various treatment groups using logistic regression to complement 
the limitation of left-censored data. The relationship between each PD parameter and $\mathrm{AUC}_{0-24 \mathrm{~h}}$ (after single-dose administrations) or $\mathrm{AUC}_{\tau, \mathrm{ss}}$ (after multiple-dose administrations) was analyzed using linear regression.

PK parameters and demographic characteristics were summarized using descriptive statistics. Dose proportionality was tested using $C_{\max }, \mathrm{AUC}_{0-24 \mathrm{~h}}, C_{\text {max,ss }}$, and $\mathrm{AUC}_{\tau, \mathrm{ss}}$ with linear regression by using log-transformed values based on the power model. ${ }^{19}$ Fisher's exact test was used to compare the continuous variables of the safety test among the treatment groups.

\section{Results}

\section{Study subjects}

Of the 121 subjects recruited for this study, 120 completed it. In the multiple-dose study, one subject who had received $200 \mathrm{mg}$ DWP05195 withdrew his informed consent on day 5 and dropped out; however, he was replaced with a new subject. The data for one subject in the $100 \mathrm{mg}$ DWP05195 multiple-dose group who did not have a peak drug concentration after the last dosing on day 8 were excluded from the PK and PD assessments.

The average age, height, and weight of subjects who completed the study were $27.1 \pm 5.1$ years, $173.3 \pm 5.4 \mathrm{~cm}$, and $68.8 \pm 7.2 \mathrm{~kg}$, respectively, in the DWP05195 treatment groups $(\mathrm{n}=96)$ and $27.4 \pm 5.0$ years, $173.1 \pm 5.6 \mathrm{~cm}$, and $68.0 \pm 6.3 \mathrm{~kg}$, respectively, in the placebo group $(\mathrm{n}=24)$. There were no significant differences in these characteristics between the placebo and DWP05195-treated groups in either the single- or multiple-dose studies.

\section{Experimental pain (PD) assessment results}

HPtr and HPtol maximally increased after $3 \mathrm{~h}$, but tended to decrease $8 \mathrm{~h}$ after a single-dose administration of DWP05195 >150 mg (Figure S1). Based on these results, blood sampling times for the PD analyses were set at $0 \mathrm{~h}$ on day 1 and at 1 and $3 \mathrm{~h}$ on day 8 in the multiple-dose study. Changes in HPtr and HPtol from the baseline values were larger in the DWP05195 treatment groups at a dose of $50 \mathrm{mg}$ $\left(1.1^{\circ} \mathrm{C}-3.3^{\circ} \mathrm{C}\right.$ and $0.9^{\circ} \mathrm{C}-1.5^{\circ} \mathrm{C}$, respectively) than those in the placebo group $\left(0.6^{\circ} \mathrm{C}\right.$ and $-0.1^{\circ} \mathrm{C}$, respectively; Table 1 and Figure S2).

Similarly, after multiple administrations of DWP05195, the HPtr and HPtol of non-sensitized ( $\mathrm{HPtr}_{\text {norm }}$ and $\mathrm{HPtol}_{\text {norm }}$ ) and capsaicin-sensitized ( $\mathrm{HPtr}_{\text {cap }}$ and $\mathrm{HPtol}_{\text {cap }}$ ) skin increased in all treatment groups within $3 \mathrm{~h}$ of administering the study drug. HPtr and HPtol values, adjusted to their respective baseline values, tended to be higher in all the DWP05195treated groups (doses over $200 \mathrm{mg}$ ) than those in the placebo group (Table 1 and Figure S3). HPtr or HPtol was sometimes measured at $50^{\circ} \mathrm{C}$ in some subjects. The number of HPtr and $\mathrm{HPtol}$ values reaching $50^{\circ} \mathrm{C}$ on normal (non-sensitized) skin increased significantly as the dose of the study drug increased $(P<0.05$, logistic regression). The PIs and FARs obtained after multiple administrations of DWP05195 (100 mg) were lower than those obtained after placebo administration. However, only differences in PIs of normal skin between the 300 mg DWP05195 dose and placebo groups were statistically significant.

Table I Summary of experimental pain (pharmacodynamic) assessment results after single- and multiple-dose administrations of DWP05I95 to healthy male subjects

\begin{tabular}{|c|c|c|c|c|}
\hline Dose group & $\Delta \mathrm{HPtr}_{\text {norm }, 3 \mathrm{~h}}$ & $\Delta \mathrm{HPtr}_{\text {cap }, 3 \mathrm{~h}}$ & $\Delta$ HPtol $_{\text {norm }, 3 \mathrm{~h}}$ & $\Delta$ HPtol $_{\text {cap }, 3 \mathrm{~h}}$ \\
\hline \multicolumn{5}{|l|}{ Single dose } \\
\hline Placebo $(n=16)$ & $0.6 \pm 2.0$ & - & $-0.1 \pm 0.9$ & - \\
\hline $10 \mathrm{mg}(\mathrm{n}=8)$ & $0.4 \pm 2.9$ & - & $0.8 \pm 1.3$ & - \\
\hline $20 \mathrm{mg}(\mathrm{n}=8)$ & $-1.2 \pm 3.7$ & - & $-0.5 \pm 1.4$ & - \\
\hline $50 \mathrm{mg}(\mathrm{n}=8)$ & $\mathrm{I} .1 \pm \mathrm{I} .7$ & - & $0.9 \pm 0.8$ & - \\
\hline 100 mg (n=8) & $2.1 \pm 1.8$ & - & $1.3 \pm 0.9$ & - \\
\hline $150 \mathrm{mg}(\mathrm{n}=8)$ & $1.0 \pm 1.8$ & - & $0.9 \pm 1.1$ & - \\
\hline $250 \mathrm{mg}(\mathrm{n}=8)$ & $2.5 \pm 1.9$ & - & $1.4 \pm 1.2$ & - \\
\hline $400 \mathrm{mg}(\mathrm{n}=8)$ & $2.0 \pm 2.9$ & - & $1.2 \pm 1.0$ & - \\
\hline $600 \mathrm{mg}(\mathrm{n}=8)$ & $3.3 \pm 3.3$ & - & $1.5 \pm 1.4$ & - \\
\hline \multicolumn{5}{|l|}{ Multiple dose } \\
\hline Placebo $(n=8)$ & $1.9 \pm 4.4$ & $1.0 \pm 1.0$ & $1.4 \pm 1.5$ & $2.3 \pm 1.8$ \\
\hline $100 \mathrm{mg}(\mathrm{n}=8)$ & $0.8 \pm 3.5$ & $2.9 \pm 2.8$ & $0.9 \pm 0.9$ & $2.8 \pm 2.5$ \\
\hline $200 \mathrm{mg}(\mathrm{n}=8)$ & $2.9 \pm 2.1$ & $5.1 \pm 2.2$ & $2.6 \pm 1.2$ & $3.5 \pm 1.9$ \\
\hline $300 \mathrm{mg}(\mathrm{n}=8)$ & $6.0 \pm 3.0$ & $2.6 \pm 2.8$ & $3.9 \pm 2.6$ & $3.5 \pm 2.4$ \\
\hline $400 \mathrm{mg}(\mathrm{n}=8)$ & $2.2 \pm 1.5$ & $2.3 \pm 3.5$ & $1.4 \pm 1.5$ & $4.4 \pm 2.9$ \\
\hline
\end{tabular}

Abbreviations: $\mathrm{HPtr}_{\text {norm' }}$, heat pain threshold in normalized skin; $\mathrm{HPtr}_{\text {cap }}$, heat pain threshold in capsaicin-sensitized skin; HPtol ${ }_{\text {norm }}$, heat pain tolerance in normalized skin; $\mathrm{HPtol}_{\text {cap }}$, heat pain tolerance in capsaicin-sensitized skin. 


\section{PK-PD relationship of DWP05 I95}

In the DWP05195-treated groups, HPtr and HPtol tended to increase with dose increments in both the single- and multiple-dose studies (Figure 1). In contrast, PI significantly decreased as the DWP0595 dose increased (Figure 2).
HPtr and HPtol significantly increased $(P<0.05)$ from their respective baseline values as DWP05195 exposure $\left(\mathrm{AUC}_{0-24 \mathrm{~h}}\right)$ increased after a single-dose administration (Figure S4). Correlations among the HPtr or HPtol of both non-sensitized and capsaicin-sensitized skins to DWP05195

A
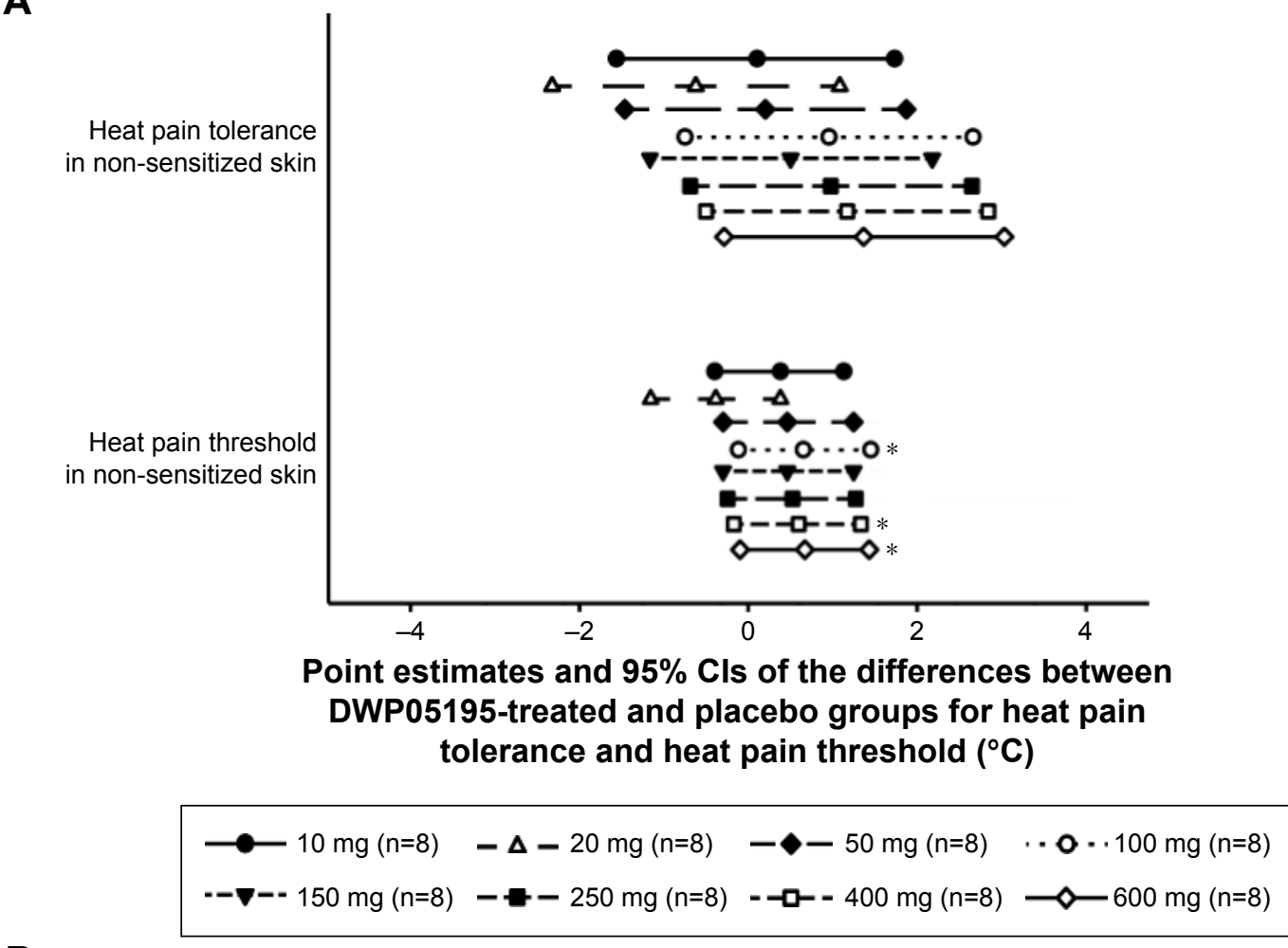

B

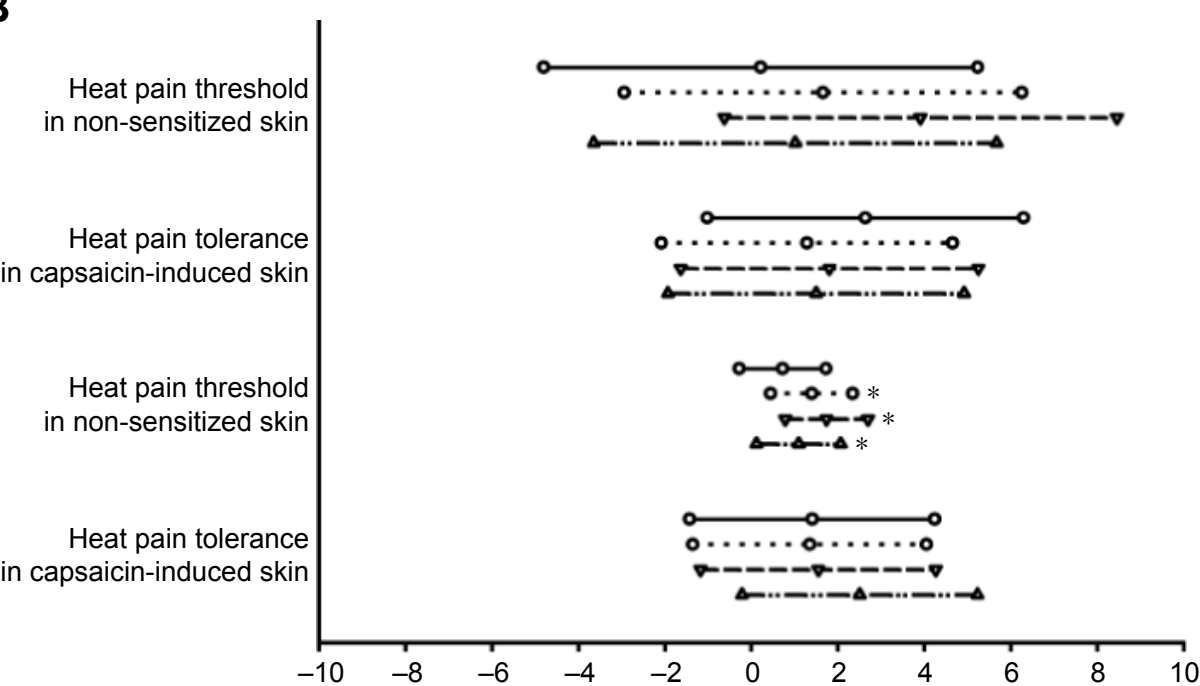

Point estimates and $95 \% \mathrm{Cls}$ of the differences between DWP05195-treated and placebo groups for heat pain tolerance and heat pain threshold $\left({ }^{\circ} \mathrm{C}\right)$

\begin{tabular}{|c|c|c|c|}
\hline$\longrightarrow 100 \mathrm{mg}(\mathrm{n}=7)$ & $\cdots \curvearrowleft \cdots 200 \mathrm{mg}(\mathrm{n}=8)$ & $\rightarrow \rightarrow-300 \mathrm{mg}(\mathrm{n}=8)$ & - \\
\hline
\end{tabular}

Figure I Point estimates and $95 \%$ confidence intervals $(\mathrm{Cls})$ of the differences between DWP05I95-treated and placebo groups for heat pain threshold and heat pain tolerance after (A) a single-dose administration and (B) multiple-dose administrations of DWP05I95 in healthy male subjects.

Note: *Indicates significant difference $(P<0.05)$ 


\section{Point estimate and $95 \%$ Cls of the differences between DWP05195-treated and placebo groups for perfusion intensity (\%)}

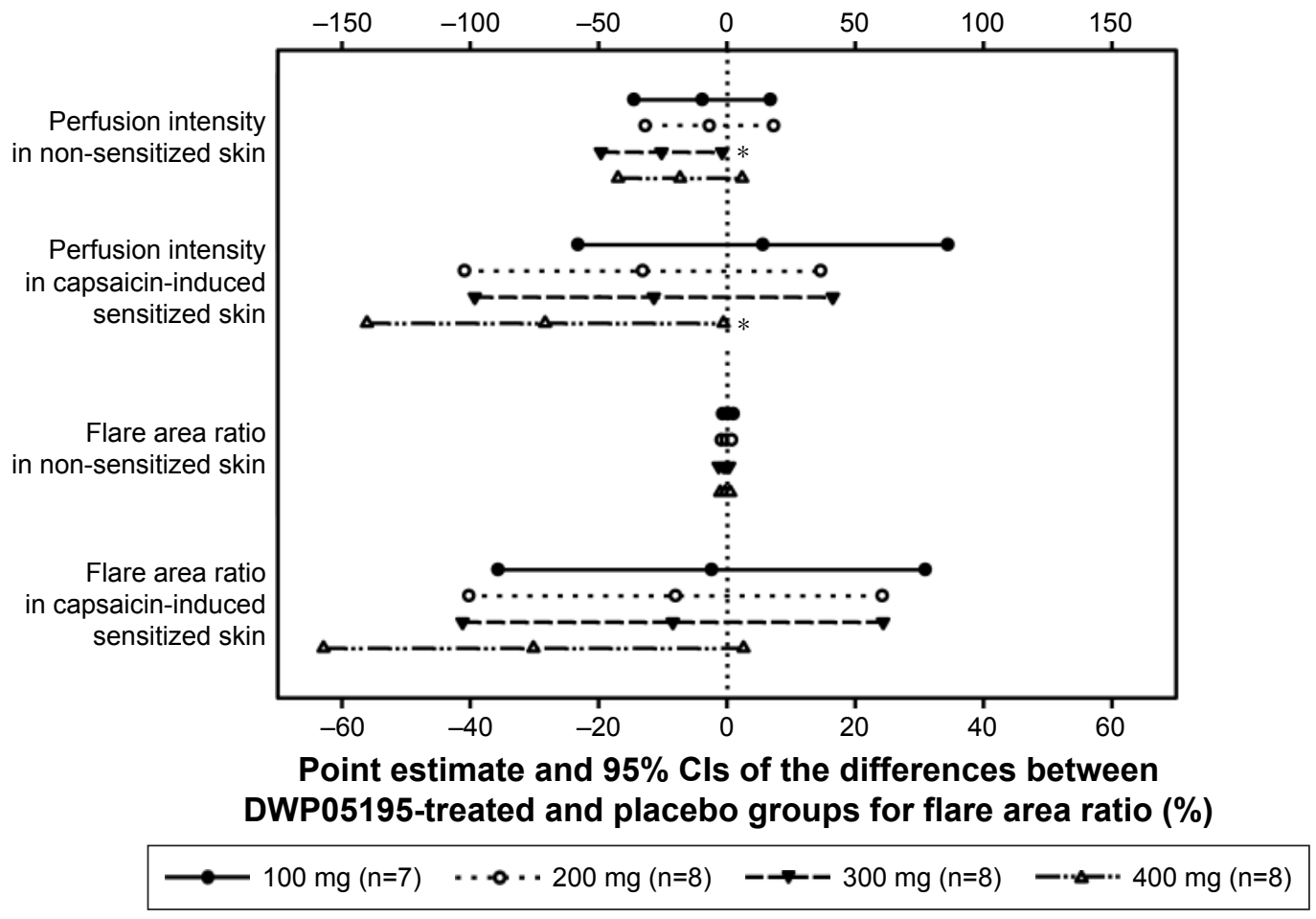

Figure 2 Point estimates and 95\% confidence intervals $(\mathrm{Cls})$ of differences between DWP05। 95 -treated and placebo groups for perfusion intensity and flare area ratio after multiple-dose administrations of DWP05I 95 in healthy male subjects.

Note: *Indicates significant difference $(P<0.05)$.

and $\mathrm{AUC}_{\tau, \mathrm{ss}}$ values trended in a positive direction; however, the values were not significant. A positive correlation between the $\mathrm{AUC}_{\tau, \mathrm{ss}}$ of DWP05195 and HPtr or HPtol in both non-sensitized and capsaicin-sensitized skins was obtained; however, it was not statistically significant.

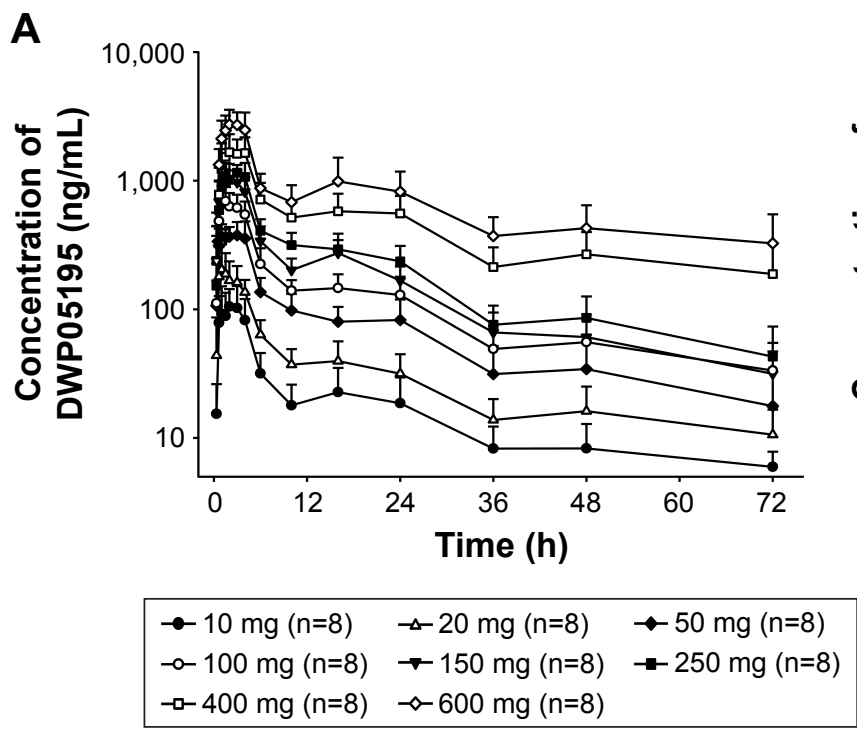

\section{PK of DWP05195}

DWP05195 was rapidly absorbed after both single-and multipledose administrations, reaching $C_{\max }$ in $\sim 1.5-3.0 \mathrm{~h}$ postdose administration (Figure 3 and Table 2). The plasma concentrations of DWP05159 were eliminated with a mean

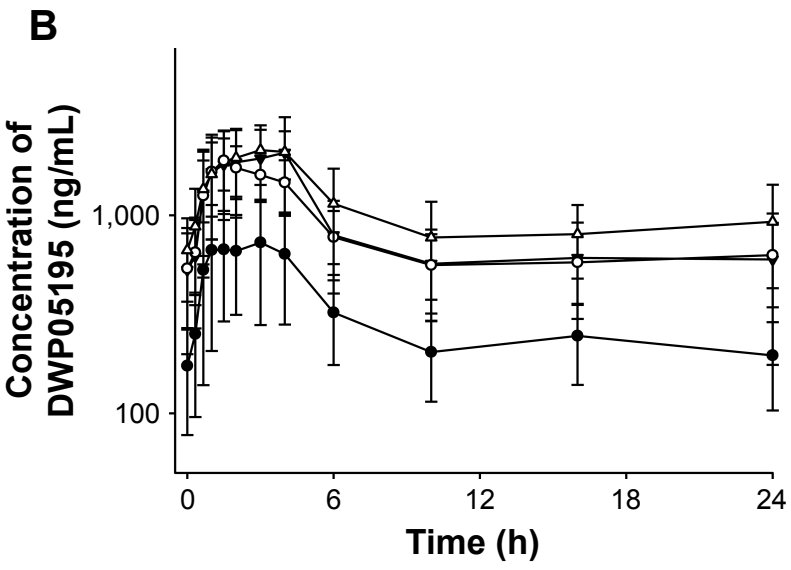

Figure 3 Mean plasma concentration-time profiles of DWP05I95 (A) from 0 to $72 \mathrm{~h}$ after a single oral dose administration and (B) at steady state after multiple oral doses from 168 to $192 \mathrm{~h}$

Note: The error bars represent standard deviations. 
Table 2 Summary of PK parameters of DWP05I95 after single- and multiple-dose administrations of DWP05I95 to healthy male subjects

\begin{tabular}{|c|c|c|c|c|c|c|}
\hline \multirow{2}{*}{$\begin{array}{l}\text { Dose } \\
\text { group }\end{array}$} & \multicolumn{6}{|c|}{ PK parameters } \\
\hline & Doses & $\mathbf{T}_{\max }(\mathbf{h})$ & $C_{\max }(\mu g / L)$ & $\mathrm{AUC}_{\text {last }}(\mu \mathrm{g} \cdot \mathrm{h} / \mathrm{L})$ & $A \cup C_{i n f}(\mu g \cdot h / L)$ & $t_{1 / 2}(\mathrm{~h})$ \\
\hline \multirow[t]{9}{*}{ Single dose } & 10 mg (n=8) & $1.5(1.0-3.0)$ & $142.1 \pm 42.4$ & I,I $172.8 \pm 547.3$ & $\mathrm{I}, 427.7 \pm 7 \mid 5.4$ & $31.1 \pm 13.5$ \\
\hline & $20 \mathrm{mg}(\mathrm{n}=8)$ & $1.0(0.7-3.0)$ & $245.8 \pm 94.4$ & $2,253.3 \pm 745.8$ & $2,968.0 \pm 1,072.4$ & $47.8 \pm 22.6$ \\
\hline & $50 \mathrm{mg}(\mathrm{n}=8)$ & $2.3(0.7-4.0)$ & $449.0 \pm 63.8$ & $5,023.9 \pm 1,786.6$ & $5,961.2 \pm 2,725.7$ & $31.5 \pm 12.2$ \\
\hline & $100 \mathrm{mg}(\mathrm{n}=8)$ & $1.5(1.0-4.0)$ & $743.9 \pm 201.5$ & $8,227.6 \pm 2,150.6$ & $10,740.9 \pm 4,300.6$ & $42.2 \pm 19.6$ \\
\hline & $150 \mathrm{mg}(\mathrm{n}=8)$ & $2.0(1.0-4.0)$ & $1,202.4 \pm 211.6$ & II,733.8 $\pm 2,354.1$ & $|3,203| \pm 2,945.4$. & $31.7 \pm 6.4$ \\
\hline & $250 \mathrm{mg}(\mathrm{n}=8)$ & $2.3(1.0-4.0)$ & $1,329.0 \pm 177.0$ & $\mid 4,459.0 \pm 2,837.3$ & $17,093.5 \pm 4,144.9$ & $31.3 \pm 22.1$ \\
\hline & $400 \mathrm{mg}(\mathrm{n}=8)$ & $2.0(1.1-4.0)$ & $2,106.7 \pm 340.8$ & $30,291.0 \pm 10,520.5$ & $43,867.4 \pm 22,980.2$ & $45.3 \pm 7.7$ \\
\hline & $600 \mathrm{mg}(\mathrm{n}=8)$ & $3.0(2.0-4.0)$ & $3,012.4 \pm 823.0$ & $47,522.3 \pm 17,555.2$ & $83,942.0 \pm 50,324.3$ & $62.8 \pm 30.1$ \\
\hline & Doses & $\mathbf{T}_{\max , s \mathrm{~s}}(\mathbf{h})$ & $C_{\max , s \mathrm{~s}}(\mu \mathrm{g} / \mathrm{L})$ & $A \cup C_{\tau, s s}(\mu g \cdot h / L)$ & $\boldsymbol{R}_{\mathrm{ac}}$ & $t_{1 / 2, \text { ss }}(h)$ \\
\hline \multirow[t]{4}{*}{ Steady state } & $100 \mathrm{mg}(\mathrm{n}=7)$ & $3.0(1.0-4.0)$ & $939.1 \pm 423.9$ & $8,327.2 \pm 2,679.6$ & $1.3 \pm 0.3$ & $36.7 \pm 16.5$ \\
\hline & $200 \mathrm{mg}(\mathrm{n}=8)$ & $1.5(1.0-4.1)$ & $I, 975 . I \pm 602.4$ & $20,040.6 \pm 5,871.6$ & $1.5 \pm 0.4$ & $49.1 \pm 35.8$ \\
\hline & $300 \mathrm{mg}(\mathrm{n}=8)$ & $3.5(0.7-4.0)$ & $2,311.7 \pm 856.9$ & $20,94 I . I \pm I 0,4 \mid 2.2$ & $1.2 \pm 0.4$ & $37.6 \pm 44.9$ \\
\hline & $400 \mathrm{mg}(\mathrm{n}=8)$ & $2.5(1.0-6.0)$ & $2,348.2 \pm 615.0$ & $24,081.6 \pm 9,393.3$ & $1.4 \pm 0.3$ & $36.4 \pm 13.3$ \\
\hline
\end{tabular}

Note: All values presented as mean $\pm S D$, except for $T_{\max }$ for which the median (range) is presented.

Abbreviations: PK, pharmacokinetic; $T_{\max }$, time to reach peak plasma drug concentrations; $C_{\max }$, maximum plasma drug concentration; $A U C C_{\text {last }}$, area under the plasma concentration-time curve from 0 to $72 \mathrm{~h} ; \mathrm{AUC}_{\text {inf }}$, area under the plasma concentration-time curve from time 0 to infinity; $t_{1 / 2}$, elimination half-life; $T_{\text {max,ss }}$, time to reach peak plasma drug concentrations at steady state; $C_{\text {max,ss }}$, maximum plasma drug concentration at steady state; $A \cup C_{\tau, s s}$, area under the plasma concentration-time curve from 0 to $24 \mathrm{~h}$ at steady state; $R_{\mathrm{ac}}$, accumulation ratio of steady state to first dose at regular administration for $\mathrm{AUC}_{\tau, \mathrm{ss}} / \mathrm{AUC}_{0-24 \mathrm{~h}}, \mathrm{AUC}_{0-24 \mathrm{~h}}$, area under the plasma concentration-time curve on day I; SD, standard deviation; $t_{1 / 2, s}$, elimination half-life at steady state.

terminal elimination half-life of 35.3-49.1 $\mathrm{h}$ after the double peaks within $24 \mathrm{~h}$. In both the single- and multiple-dose studies, $C_{\max }$ and $\mathrm{AUC}_{\text {last }}$ increased as the dose of DWP05195 was increased. In the single-dose study, $C_{\max }$ and $\mathrm{AUC}_{\text {last }}$ were not proportional to the administered dose, as the $95 \%$ confidence intervals (CIs) of the slope gradients did not include 1.0. However, the $\mathrm{AUC}_{\text {last }}$ was nearly dose proportional as the $95 \%$ CIs ranged from 0.81 to 0.95 . In the multiple-dose study, both $C_{\text {max,ss }}$ and $\mathrm{AUC}_{\tau, \mathrm{ss}}$ values confirmed dose proportionality based on the finding that the $95 \%$ CIs of the slopes of the log-transformed $C_{\text {max,ss }}$ and $\mathrm{AUC}_{\tau, \mathrm{ss}}$ included $1.0\left(C_{\text {max,ss }}\right.$ : $0.55-1.26$ and $\left.\mathrm{AUC}_{\tau, \mathrm{ss}}: 0.54-1.25\right)$ in the power model. The mean accumulation ratio was 1.16-1.57 after multiple doses of DWP05195 (100-400 mg) were administered, and no trend was observed as the dose was increased. The fraction of unchanged drug excreted in urine was $<0.1 \%$ in both the single- and multiple-dose studies.

\section{Safety and tolerability of DWP05 I95}

In the single-dose study, 31 out of 80 subjects experienced 51 drug-related AEs (ie, adverse drug reactions [ADRs]) throughout the study. No serious events were reported during the study. Increases in body temperatures (to $38^{\circ} \mathrm{C}$ and $>38.0^{\circ} \mathrm{C}-38.3^{\circ} \mathrm{C}$ ) were reported in two and three subjects in the 400 and $600 \mathrm{mg}$ dose groups, respectively. The body temperature tended to increase with the DWP05195 dose as shown in Figure S5. In the multiple-dose study, 36 out of 41 subjects experienced 305 ADRs throughout the study (Table S1). Hyperthermia (a temperature $>38^{\circ} \mathrm{C}$ ) was reported once $\left(38.3^{\circ} \mathrm{C}\right)$ in the $400 \mathrm{mg}$ dose group.

In both single- and multiple-dose studies, the percentage of ADR cases significantly increased as the dose of DWP05195 increased $(P<0.05)$. All reported AEs were mild to moderate in severity and resolved without medication or therapy. There were no abnormal results from the laboratory tests, physical examinations, or ECGs.

\section{Discussion}

This is the first study to evaluate the PD, PK, safety, and tolerability of different doses of DWP05195 in human subjects. Increases in HPtr and HPtol were higher in the DWP05195treated groups than in the placebo group. PI and FAR decreased as the dose of DWP05195 increased. Increasing trends in HPtr and HPtol after multiple doses of DWP05195 are administered have also been observed in previous preclinical studies. However, HPtr and HPtol also increased from their respective baseline values after placebo administration. The increase is anticipated to have been caused by diurnal variations in pain perception and thermal sensitivity. ${ }^{20-22}$ Increased HPtr and HPtol have been consistently reported in previous studies with other TRPV1 antagonists such as SB-705498 (GlaxoSmithKline, London, UK) and AZD-1386 (AstraZeneca, London, UK). ${ }^{23}$

In the present study, the application of capsaicin proved to be methodologically beneficial for reducing the incidence of censored data by decreasing the overall HPtol and HPtr. ${ }^{24-26}$ 
To prevent skin injury while measuring HPtr and HPtol, the cutoff temperature was set at $50^{\circ} \mathrm{C}$ and measurements were suspended when the $50^{\circ} \mathrm{C}$ limit was reached. The measured $\mathrm{HPtr}$ and HPtol values reached the $50^{\circ} \mathrm{C}$ limit as the dose of DWP05195 increased; however, this occurred more often in the normal skin than in the capsaicin-sensitized skin. This indicates that a more accurate evaluation of HPtr and HPtol was achieved because capsaicin was applied to the skin. ${ }^{26}$

TRPV1 is involved in thermoregulation. This may be the reason for the large number of thermoregulation-related AEs observed in the present study, such as "feeling cold", "feeling hot", and peripheral coldness. Changes in thermoregulatory function were also observed in some previous preclinical studies on TRPV1. ${ }^{27,28}$ The TRPV1 channel is present in neurons in the preopticohypothalamic area, which is involved in thermoregulatory pathways mediated by medial preoptic nucleus cells or gamma-aminobutyric acid (GABA)ergic myeloperoxidase cells..$^{29,30}$

In the present study, an increasing trend in body temperature after administration of DWP05195 was observed, and five cases of hyperthermia (maximum $38.3^{\circ} \mathrm{C}$ ) were reported. This finding has been reported in previous studies with other TRPV1 antagonists. A previously reported clinical study with AMG-517 (Amgen, Thousand Oaks, CA, USA) resulted in plasma concentration-dependent hyperthermia; the maximal body temperature was recorded as $39.9^{\circ} \mathrm{C} .{ }^{31}$ A Phase 1 study of AZD-1386 (doses ranging from 3 to $190 \mathrm{mg}$ and 20 to $150 \mathrm{mg}$ in a single-dose and multiple-dose study, respectively) reported an induction of hyperthermia in healthy subjects. When compared to previous studies, the hyperthermia cases in this study were mild and less frequently observed. However, careful investigation of hyperthermia is required for further evaluation of DWP05195.

Since this is a first-in-human study, the administered doses of DWP05195 were decided based on no observed adverse effect levels (NOAELs) derived from a 4-week preclinical trial conducted in Sprague Dawley rats and beagle dogs (75 and $50 \mathrm{mg} / \mathrm{kg}$, respectively). The NOAELs were then converted to human equivalent doses in line with the guidelines specified by the US Food and Drug Administration $^{32,33}$ and adjusted using safety factors. Consequently, a $72 \mathrm{mg}$ dose was set as the maximum recommended starting dose (MRSD) to be administered to healthy adult male subjects weighing $60 \mathrm{~kg}$. In addition, in a preclinical efficacy trial conducted in a rat model of diabetic neuropathy, a minimal effective dose (MED) of $1 \mathrm{mg} / \mathrm{kg}$ was obtained for DWP05195, which converts to $9.6 \mathrm{mg}$ for a healthy adult male subject weighing $60 \mathrm{~kg}$. Considering the abovementioned MRSD and MED values derived from nonclinical studies, the starting dose of DWP05195 was set at $10 \mathrm{mg}$. In addition, dose increments were planned from 10 to $20,50,100,150,250,400$, and $600 \mathrm{mg}$ (unpublished internal data).

\section{Conclusion}

Subjects who were administered DWP05195 showed relatively higher HPtr and HPtol as well as lower PI and FAR than did those who were administered the placebo. This indicates that DWP05195 is a TRPV1 antagonist. Given the near dose-proportional systemic exposure observed in the single- and multiple-dose studies, systemic exposure is expected to increase as the dose of DWP05195 is increased. DWP05195 was well tolerated at 10-600 mg after a single oral dose and at 100-400 mg/day for 8 days after multiple oral doses were administered to healthy volunteers.

\section{Acknowledgments}

This study was sponsored by Daewoong Pharmaceutical Co., Ltd. (Seoul, South Korea). An abstract of this paper was presented at the ASCPT 2016 Annual Meeting as a poster presentation with interim findings. The poster's abstract was published in "Poster Abstracts" in Clinical Pharmacology and Therapeutics: http://onlinelibrary.wiley. com/doi/10.1002/cpt.310/full. The actual paper, however, has never been published.

\section{Disclosure}

Hee Sun Kim and Ji Duck Kim are employees of Daewoong Pharmaceutical Co., Ltd. (Seoul, Republic of Korea). The other authors report no conflicts of interest in this work.

\section{References}

1. Mäntyselkä P, Kumpusalo E, Ahonen R, et al. Pain as a reason to visit the doctor: a study in Finnish primary health care. Pain. 2001;89(2-3): 175-180.

2. Gøtzsche PC. NSAIDs. BMJ Clin Evid. 2010;2010:1108.

3. Potter MB. NSAIDs alone or with opioids as therapy for cancer pain. Am Fam Physician. 2005;72(3):436-437.

4. Moore RA, Chi CC, Wiffen PJ, Derry S, Rice AS. Oral nonsteroidal anti-inflammatory drugs for neuropathic pain. Cochrane Database Syst Rev. 2015;10:CD010902.

5. Cepeda MS, Farrar JT, Baumgarten M, Boston R, Carr DB, Strom BL. Side effects of opioids during short-term administration: effect of age, gender, and race. Clin Pharmacol Ther. 2003;74(2):102-112.

6. Palos GR. Opioids and cancer survivors: issues in side-effect management. Oncol Nurs Forum. 2008;35(supp1):13-19.

7. Berde C, Nurko S. Opioid side effects - mechanism-based therapy. N Engl J Med. 2008;358:2400-2402.

8. Kamei T, Miyauchi M, Oyamada Y, Shimizu I. Novel therapeutic approach to neuropathic pain: "Hot" and "Cool" TRP-channel family. Nihon Yakurigaku Zasshi. 2012;140(5):196-200. 
9. Rashid MH, Inoue M, Kondo S, Kawashima T, Bakoshi S, Ueda H. Novel expression of vanilloid receptor 1 on capsaicin-insensitive fibers accounts for the analgesic effect of capsaicin cream in neuropathic pain. J Pharmacol Exp Ther. 2003;304(3):940-948.

10. Caterina MJ, Leffler A, Malmberg AB, et al. Impaired nociception and pain sensation in mice lacking the capsaicin receptor. Science. 2000; 288(5464):306-313.

11. Staaf S, Oerther S, Lucas G, Mattsson JP, Ernfors P. Differential regulation of TRP channels in a rat model of neuropathic pain. Pain. 2009;144(1-2):187-199.

12. Dyachenko IA, Andreev YA, Logashina YA, Murashev AN, Grishin EV. Biological activity of a polypeptide modulator of TRPV1 receptor. Dokl Biol Sci. 2015;465(1):279-281.

13. Appendino G, De Petrocellis L, Trevisani M, et al. Development of the first ultra-potent "capsaicinoid" agonist at transient receptor potential vanilloid type 1 (TRPV1) channels and its therapeutic potential. J Pharmacol Exp Ther. 2005;312(2):561-570.

14. Cortright DN, Crandall M, Sanchez JF, Zou T, Krause JE, White G. The tissue distribution and functional characterization of human VR1. Biochem Biophys Res Commun. 2001;281(5):1183-1189.

15. Hudson LJ, Bevan S, Wotherspoon G, Gentry C, Fox A, Winter J. VR1 protein expression increases in undamaged DRG neurons after partial nerve injury. Eur J Neurosci. 2001;13(11):2105-2114.

16. Shukla G, Bhatia M, Behari M. Quantitative thermal sensory testing value of testing for both cold and warm sensation detection in evaluation of small fiber neuropathy. Clin Neurol Neurosurg. 2005;107(6): 486-490.

17. Ravn P, Frederiksen R, Skovsen AP, Christrup LL, Werner MU. Prediction of pain sensitivity in healthy volunteers. J Pain Res. 2012;5: 313-326.

18. Tjølsen A, Rosland JH, Berge OG, Hole K. The increasing-temperature hot-plate test: an improved test of nociception in mice and rats. J Pharmacol Methods. 1991;25(3):241-250.

19. Smith BP, Vandenhende FR, DeSante KA, et al. Confidence interval criteria for assessment of dose proportionality. Pharm Res. 2000;17(10): 1278-1283.

20. Koch HJ, Raschka C, Fischer-Barnicol D, Lanquillon S, Ibach B. Diurnal variation of pain perception and heart rate in the human tourniquet pain model in healthy volunteers. Psychiatr Prax. 2004; 31(suppl 1):S155-S157.
21. Krøigård T, Sothynathan I, Sindrup SH. Intraindividual variability and long-term changes of thermal quantitative sensory testing. J Clin Neurophysiol. 2015;32(4):352-356.

22. Strian F, Lautenbacher S, Galfe G, Hölzl R. Diurnal variations in pain perception and thermal sensitivity. Pain. 1989;36(1):125-131.

23. Gomtsyan A, Brederson JD. Clinical and preclinical experience with TRPV1 antagonists as potential analgesic agents. In: Szallasi A, editor. TRP Channels as Therapeutic Targets: From Basic Science to Clinical Use. New York: Academic Press; 2015:129-139.

24. Cavallone LF, Frey K, Montana MC, et al. Reproducibility of the heat/ capsaicin skin sensitization model in healthy volunteers. J Pain Res. 2013;6:771-784

25. Dirks J, Petersen KL, Dahl JB. The heat/capsaicin sensitization model: a methodologic study. J Pain. 2003;4(3):122-128.

26. Flühr K, Neddermeyer TJ, Lötsch J. Capsaicin or menthol sensitization induces quantitative but no qualitative changes to thermal and mechanical pain thresholds. Clin J Pain. 2009;25(2):128-131.

27. Garami A, Pakai E, Oliveira DL, et al. Thermoregulatory phenotype of the Trpv1 knockout mouse: thermoeffector dysbalance with hyperkinesis. J Neurosci. 2011;31(5):1721-1733.

28. Gavva NR, Bannon AW, Hovland DN Jr, et al. Repeated administration of vanilloid receptor TRPV1 antagonists attenuates hyperthermia elicited by TRPV1 blockade. J Pharmacol Exp Ther. 2007;323(1):128-137.

29. Morrison SF, Nakamura K. Central neural pathways for thermoregulation. Front Biosci (Landmark Ed). 2011;16:74-104.

30. Romanovsky AA, Almeida MC, Garami A, et al. The transient receptor potential vanilloid-1 channel in thermoregulation: a thermosensor it is not. Pharmacol Rev. 2009;61(3):228-261.

31. Chizh BA, O'Donnell MB, Napolitano A, et al. The effects of the TRPV1 antagonist SB-705498 on TRPV1 receptor-mediated activity and inflammatory hyperalgesia in humans. Pain. 2007;132(1-2):132-141.

32. Imam MT, Venkateshan SP, Tandon M, Saha N, Pillai KK. Comparative evaluation of US Food and Drug Administration and pharmacologically guided approaches to determine the maximum recommended starting dose for first-in-human clinical trials in adult healthy men. J Clin Pharmacol. 2011;51(12):1655-1664.

33. Chan G, Gray P, Glue P. An evaluation of the FDA draft guidance for estimating the maximum recommended starting dose (MRSD) for first-in-human (FIH) studies. Clin Pharmacol Ther. 2004;75(2):8. 


\section{Supplementary materials}
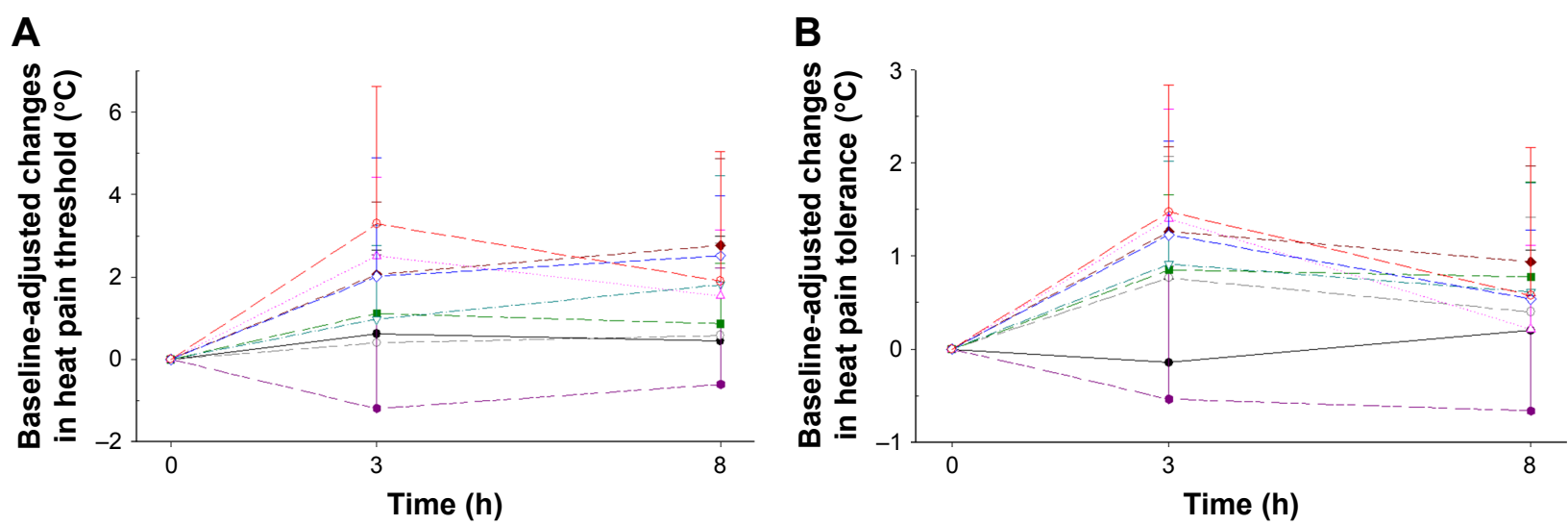

\begin{tabular}{|c|c|c|c|c|}
\hline$\longrightarrow \quad$ Placebo $(n=16)$ & $\begin{aligned} & 10 \mathrm{mg}(\mathrm{n}=8) \\
& 250 \mathrm{mg}(\mathrm{n}=8)\end{aligned}$ & $-120 \mathrm{mg}(\mathrm{n}=8)$ & $\ldots-\ldots-n g(n=8)$ & $100 \mathrm{mg}(\mathrm{n}=8)$ \\
\hline
\end{tabular}

Figure SI Baseline-adjusted (A) heat pain threshold and (B) heat pain tolerance among dose groups after a single oral dose of DWP05I95 was administered to healthy male subjects.

Note: The error bars represent the standard deviation at each sampling time.

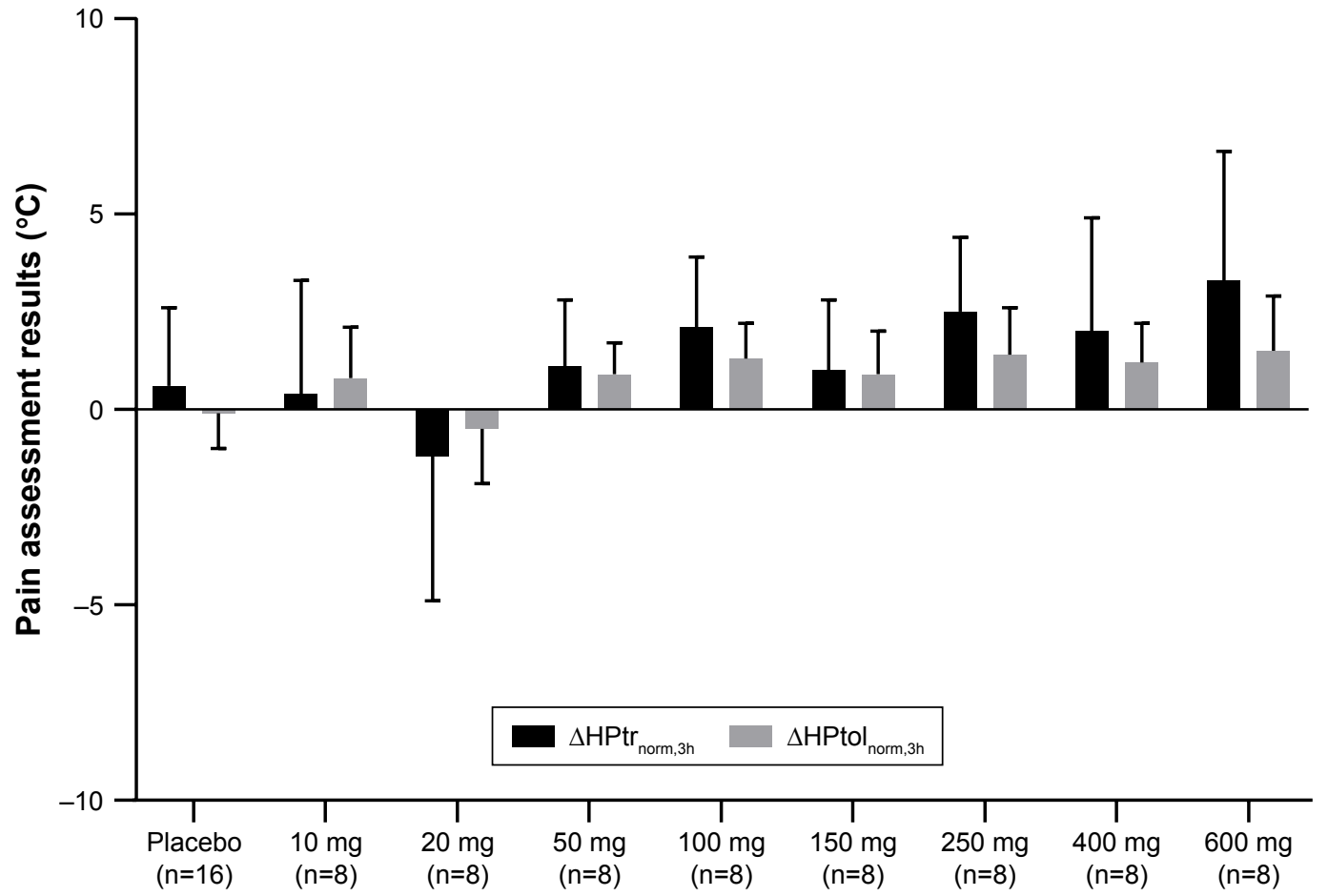

Figure S2 Experimental pain assessment results of the single-dose study.

Notes: HPtr and HPtol in normalized skin $3 \mathrm{~h}$ after a single-dose administration are shown. The error bars denote standard deviations.

Abbreviations: HPtr, heat pain threshold; HPtol, heat pain tolerance. 

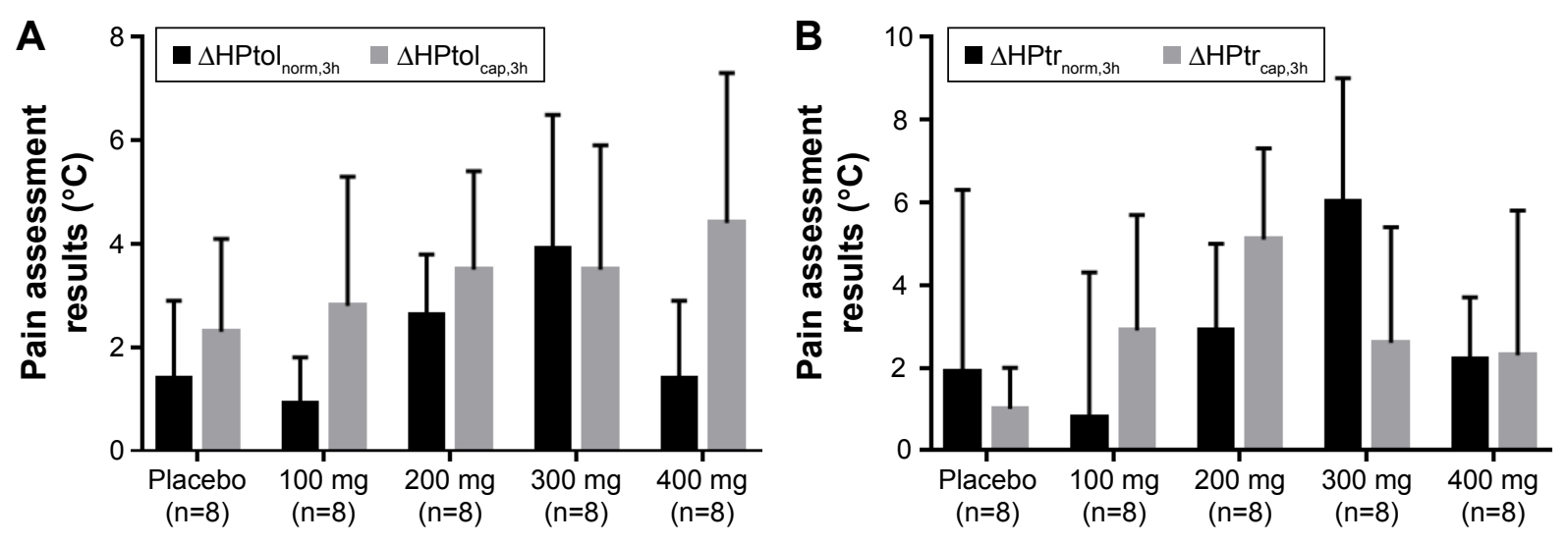

Figure S3 Experimental pain assessment results from the multiple-dose studies.

Notes: (A) HPtr in normalized skin and in capsaicin-sensitized skin $3 \mathrm{~h}$ after drug administration is shown. (B) HPtol in normalized skin and in capsaicin-sensitized skin $3 \mathrm{~h}$ after administration of multiple doses is shown. The error bars denote the standard deviations.

Abbreviations: HPtr, heat pain threshold; HPtol, heat pain tolerance.

A

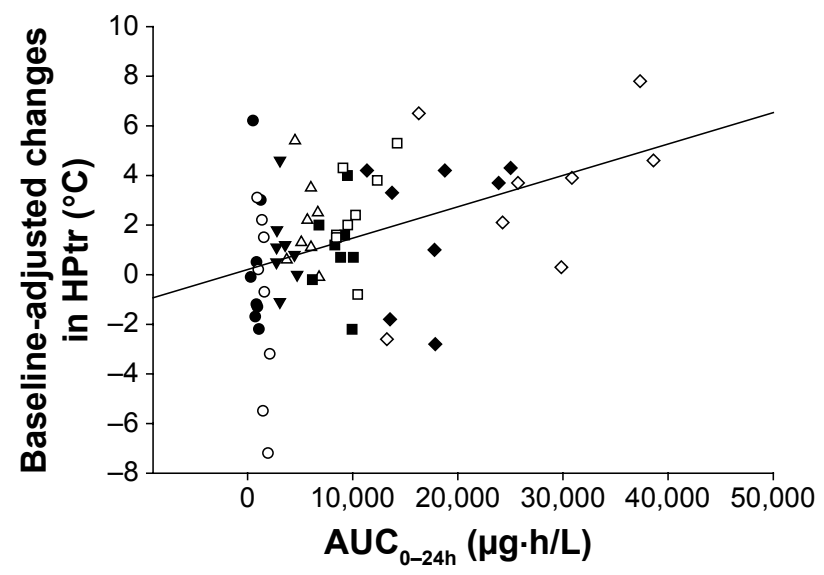

B

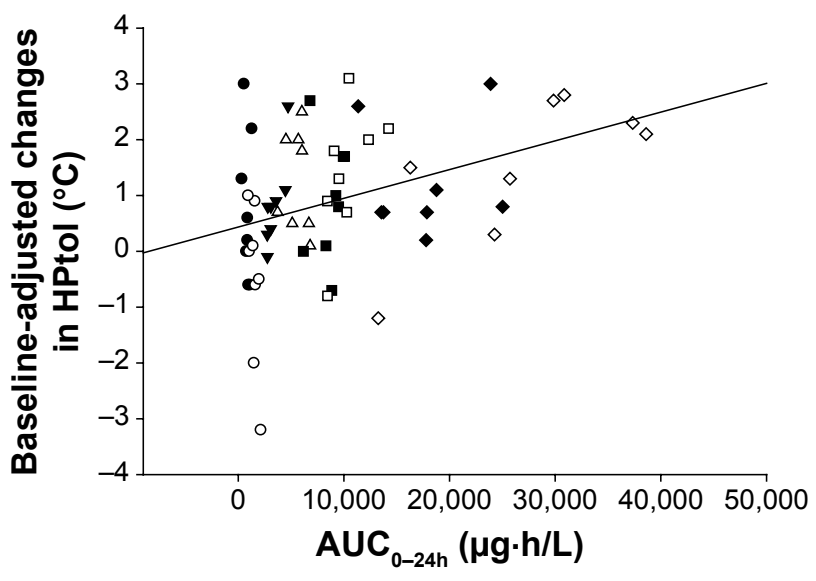

- $10 \mathrm{mg}(\mathrm{n}=8) \quad \circ 20 \mathrm{mg}(\mathrm{n}=8) \quad \nabla 50 \mathrm{mg}(\mathrm{n}=8) \quad \Delta 100 \mathrm{mg}(\mathrm{n}=8)$

- $150 \mathrm{mg}(\mathrm{n}=8) \quad$ 口 $250 \mathrm{mg}(\mathrm{n}=8) \quad \diamond 400 \mathrm{mg}(\mathrm{n}=8) \quad \diamond 600 \mathrm{mg}(\mathrm{n}=8)$

Figure S4 Correlation between baseline-adjusted changes in (A) HPtr and (B) HPtol $3 \mathrm{~h}$ after a single dose of DWP05I95 or placebo was administered to healthy male subjects.

Abbreviations: HPtr, heat pain threshold; HPtol, heat pain tolerance; $\mathrm{AUC}_{0-24 \mathrm{~h}}$, area under the plasma concentration-time curve on day I. 

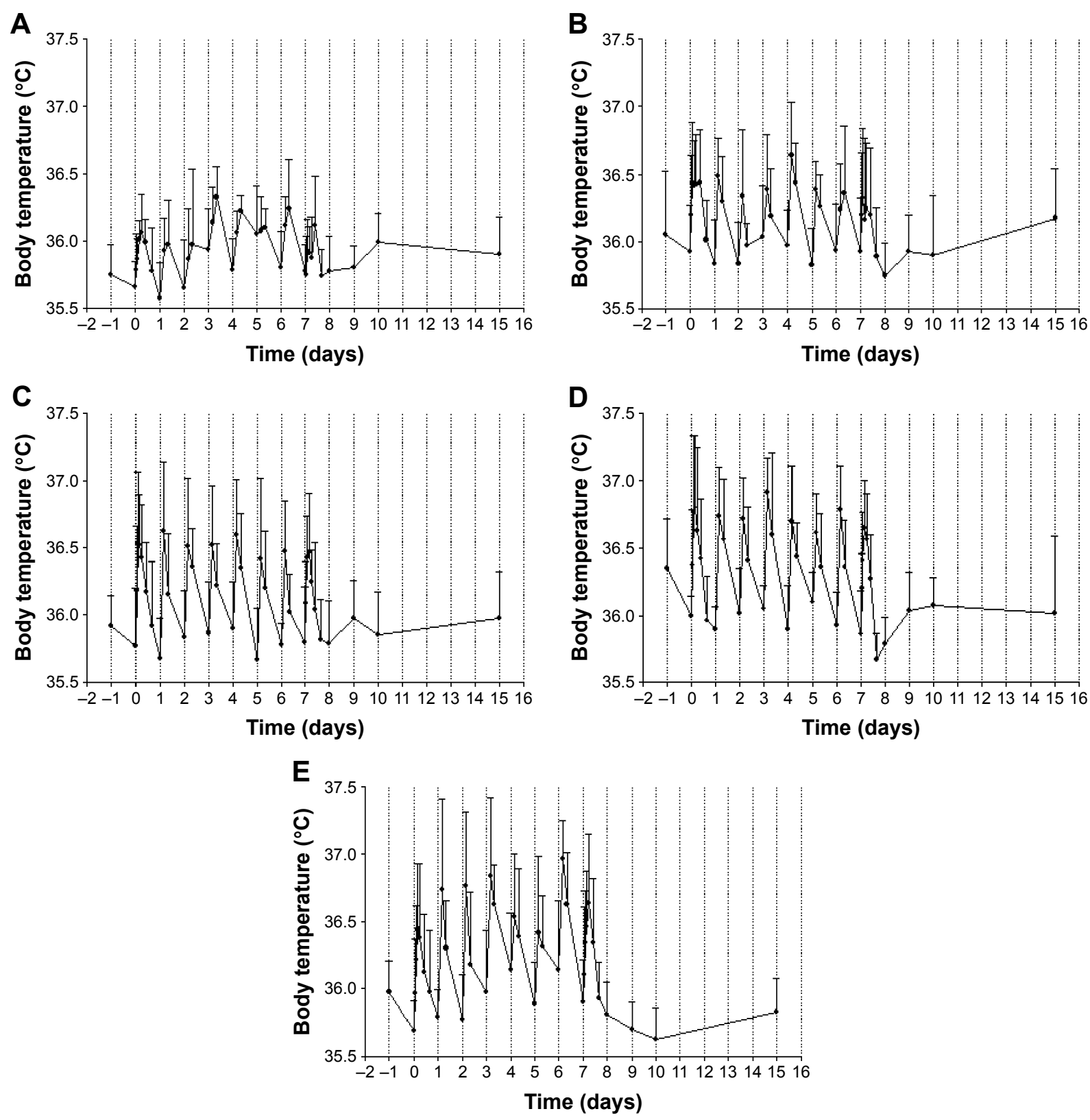

Figure S5 Body temperature-time profiles after multiple administrations of study drug.

Notes: (A) Placebo, (B) DWP05 195100 mg, (C) DWP05I 95200 mg, (D) DWP05I 95300 mg, and (E) DWP05I95 400 mg. The error bars represent the standard deviation at each sampling time. 
Table SI Summary of AEs

\begin{tabular}{|c|c|c|}
\hline Dose group & Drug-related AEs & Common drug-related AEs* \\
\hline \multicolumn{3}{|c|}{ Single-dose study } \\
\hline \multicolumn{3}{|c|}{ DWP05195 } \\
\hline $10 \mathrm{mg}(\mathrm{n}=8)$ & $I(1)$ & Feeling hot ( $12.5 \%)$ \\
\hline $20 \mathrm{mg}(\mathrm{n}=8)$ & $0(0)$ & \\
\hline $50 \mathrm{mg}(\mathrm{n}=8)$ & $2(2)$ & Feeling cold (25.0\%) \\
\hline $100 \mathrm{mg}(\mathrm{n}=8)$ & $0(0)$ & \\
\hline $150 \mathrm{mg}(\mathrm{n}=8)$ & $2(2)$ & Feeling cold (I2.5\%) \\
\hline $250 \mathrm{mg}(\mathrm{n}=8)$ & II (7) & Feeling cold $(50.0 \%)$, feeling hot $(37.5 \%)$ \\
\hline $400 \mathrm{mg}(\mathrm{n}=8)$ & $13(7)$ & Feeling cold (62.5\%), paresthesia (37.5\%), pyrexia (25.0\%), headache $(25.0 \%)$, feeling hot $(12.5 \%)$ \\
\hline $600 \mathrm{mg}(\mathrm{n}=8)$ & $17(8)$ & Feeling cold (100.0\%), pyrexia (37.5\%), headache (25.0\%), feeling hot (I2.5\%), paresthesia (I2.5\%) \\
\hline Placebo $(n=16)$ & $4(5)$ & Headache (12.5\%), feeling hot $(6.25 \%)$ \\
\hline \multicolumn{3}{|c|}{ Multiple-dose study } \\
\hline \multicolumn{3}{|c|}{ DWP05I95 } \\
\hline $100 \mathrm{mg}(\mathrm{n}=8)$ & $8(8)$ & Feeling cold (37.5\%), feeling hot (25.0\%) \\
\hline $200 \mathrm{mg}(\mathrm{n}=9)$ & $71(9)$ & Feeling cold (100.0\%), feeling hot (55.6\%), headache $(22.2 \%)$ \\
\hline $300 \mathrm{mg}(\mathrm{n}=8)$ & $83(8)$ & Feeling cold ( $100.0 \%)$, headache (37.5\%), hyperhidrosis ( $25.0 \%)$, feeling hot $(25.0 \%)$ \\
\hline \multirow[t]{2}{*}{$400 \mathrm{mg}(\mathrm{n}=8)$} & $115(8)$ & Feeling cold ( $100.0 \%)$, feeling hot (50.0\%) \\
\hline & & Hyperhidrosis $(50.0 \%)$, headache $(25.0 \%)$ \\
\hline Placebo $(n=8)$ & $16(5)$ & Peripheral coldness $(25.0 \%)$, headache $(25.0 \%)$ \\
\hline
\end{tabular}

Notes: All values are presented as the number of AEs (number of subjects with AEs). The AE was countered as drug related when its causality assessment was certain, probable, or possible. *Common AEs ( $>5 \%$ incidence for single-dose study and $>20 \%$ incidence for multiple-dose study) were presented with incidence, (number of subjects with $A E s /$ number of subjects) $\times 100$, in each dosage group.

Abbreviation: AEs, adverse events.

\section{Publish your work in this journal}

Drug Design, Development and Therapy is an international, peerreviewed open-access journal that spans the spectrum of drug design and development through to clinical applications. Clinical outcomes, patient safety, and programs for the development and effective, safe, and sustained use of medicines are the features of the journal, which has also been accepted for indexing on PubMed Central. The manuscript management system is completely online and includes a very quick and fair peer-review system, which is all easy to use. Visit http://www.dovepress.com/testimonials.php to read real quotes from published authors.

Submit your manuscript here: http://www.dovepress.com/drug-design-development-and-therapy-journal 